Canadian Food Studies

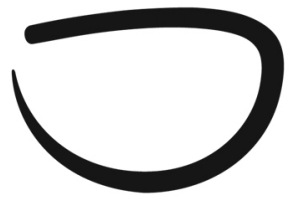

La Revue canadienne des études sur l'alimentation

Original Research Article

\title{
Building effective relationships for community-engaged scholarship in Canadian food studies
}

Peter Andrée1, Dayna Chapman², Louisa Hawkins³ ${ }^{3}$ Cathleen Kneen 4 , Wanda Martin ${ }^{5}$, Christina Muehlberger ${ }^{6}$, Connie Nelson ${ }^{7}$, Katherine Pigott $^{8}$, Wajma Qaderi-Attayi ${ }^{9}$, Steffanie Scott ${ }^{10}$, \& Mirella Stroink ${ }^{11}$

'Department of Political Science, Carleton University (corresponding author: Peter.Andree@carleton.ca) ${ }^{2}$ BC Food Systems Network ${ }^{3}$ Department of Sociology and Anthropology, Carleton University ${ }^{4}$ The Ram's Horn

${ }^{5}$ College of Nursing, University of Saskatchewan ${ }^{6}$ Department of Sociology and Anthropology, Carleton University ${ }^{7}$ Food Security Research Network \& Lakehead University ${ }^{8}$ Healthy Eating and Active Communities, Region of Waterloo Public Health ${ }^{9}$ Guelph Community Health Centre ${ }^{10}$ Department of Geography \& Environmental Management, University of Waterloo ${ }^{11}$ Department of Psychology, Lakehead University

\begin{abstract}
How can community-engaged scholars best undertake grounded, policy-relevant, food systems research and teaching in ways that support the capacity of —and meaningfully build on-the experiences of civil society organizations working on these issues in Canada? This paper analyzes four case studies in the context of a research project that brings together members of the Canadian Association for Food Studies and Food Secure Canada. One case was led by Region of
\end{abstract}


Waterloo Public Health and faculty from the University of Waterloo; a second by the Food Security Research Network at Lakehead University in Thunder Bay and the North Superior Workforce Planning Board; a third by the national student organization Meal Exchange and Ryerson University in Toronto; and a fourth by the BC Food Systems Network. We argue that the answer to the question above lies in establishing respectful relationships and recognizing the different cultures involved, and we offer five methodological insights for building effective relationships in practice. The first is the need to disaggregate the concept of 'community' in order to acknowledge the distinct needs and assets of the diverse organizations and populations involved. Our second and third insights are linked: Establish the relationship around a shared vision, and then negotiate mutually-beneficial teaching or research projects. Fourth, practitioners should approach community-campus engagement through the framework of contextual fluidity, which includes seeing the relationships and the vision at the heart of the work, while remaining open to shifts and new opportunities. Finally, adopting community capacity building practices helps practitioners realize their shared vision.

Keywords: community engaged scholarship, community service learning, community-based research, participatory action research, community food security, community-campus engagement

Acronyms used in this article:

BCFSN: British Columbia Food Systems Network

CAFS: Canadian Association for Food Studies

CFICE: Community First: Impacts of Community Engagement

CFS: Community Food Security

FSC: Food Secure Canada

\section{Introduction}

In 2001, a group of community food activists, food policy analysts and academics from a variety of disciplines came together in a national alliance to address food issues in Canada. This gave birth to two sister organizations, the Canadian Association for Food Studies (CAFS), formed in 2005, and Food Secure Canada (FSC), officially incorporated in 2006. The mission of CAFS states that it "recognizes the need for coordinated interdisciplinary research efforts in response to societal needs for informing policy makers, assessing the outcomes of community-based work, and demonstrating the environmental and social impacts of changes affecting food systems and food policies” (CAFS, 2013). FSC has a more activist bent. It is “a Canada-wide alliance of civil society organizations ${ }^{1}$ and individuals collaborating to advance dialogue and cooperation for policies and programs that improve food security in Canada and globally” (FSC, 2013). ${ }^{2}$

Our work builds on the culture of engagement that already exists between CAFS and FSC, and seeks to identify how this emergent 'community of practice' linked to Canada's

\footnotetext{
${ }^{1}$ Civil society organizations are defined broadly in this article as all of those formal and informal organizations, lying between the individual and the state, through which people come together to work on social and political change.

${ }^{2}$ While these two organizations operate independently, over the last nine years CAFS and FSC have shared board members, and each has actively encouraged participation by its members in the other's meetings.
} 
growing food movement can be expanded and its work refined. Specifically, we ask: How can researchers - whether campus or community-based — best undertake grounded, policy-relevant, food systems scholarship in ways that support the capacity of, and meaningfully build on the experiences of, the types of civil society organizations that are brought together under the umbrella of FSC? We argue that effective community-campus engagement in both teaching and research involves building respectful relationships and trust, and we offer five methodological insights for establishing such relationships in practice. This paper arrives at these insights by bringing the literature on community engaged scholarship — especially the 'recipe' for community-academic partnerships to help build food security developed by Nelson, Stadey, and Lyons (2005) - into dialogue with reflections on four diverse case studies. These studies were carried out in 2012-13 through the Community Food Security hub (CFS hub) of the Community First: Impacts of Community Engagement (CFICE) research project based at Carleton University, Ottawa.

CFICE's overall mandate is to dig into the details of: how civil society organizations define, evaluate, and utilize the value created by community-campus engagement; how this work can take place across various scales; and how they can best participate in the design of engagement activities. We are also exploring ways to address the many ethical issues involved in collaboration in teaching and research, especially when working with vulnerable groups or working cross-culturally. CFICE research is being carried out by four issue-based hubs in the areas of Poverty Reduction, Community Environmental Sustainability, Violence Against Women, and Community Food Security—with a fifth focused on knowledge mobilization across the project. The CFS hub understands community food security as a "condition in which all community residents obtain a safe, culturally appropriate, nutritionally sound diet through an economically and environmentally sustainable food system that maximizes community selfreliance, social justice, and democratic decision making” (Hamm \& Bellows, 2003, p. 37), and respects the approach of food sovereignty. To help make community food security a reality in Canada, the CFS hub seeks to build stronger links between research and policy advocacy, and to increase recognition of the research capacity of civil society organizations (particularly of those working at the grassroots level). It also strives to ensure that students are given the best possible grounding in the 'real world' experiences of organizations working to build healthy, just, and sustainable food systems in Canada. Our ultimate goal is the adoption of food sovereignty policies which better meet the needs of all those currently marginalized in the dominant food systems by governments, among others. To make all of this happen, Food Secure Canada is one of the core partners in the CFS hub, and CFICE enables FSC staff to coordinate some of the activities of the hub, including the virtual Community-Academic Collaborative network which holds periodic webinars to share the lessons of collaborative projects. ${ }^{3}$

\section{The theory and practice of effective community-campus engagement}

There is a long history of practice and theorizing in the field of community-engaged scholarship. The US-based Commission on Community Engaged Scholarship in the Health Professions (2005) defines Community Engaged Scholarship as "scholarship that involves the faculty member in a mutually beneficial partnership with the community" and notes that it often

\footnotetext{
${ }^{3}$ To join the Community Academic Collaborative, go to foodsecurecanada.org
} 
involves a variety of practices, including community service learning, community-based research, and participatory action research. Community service learning is an "educational approach that integrates service in the community with intentional learning activities" (CACSL, 2013). Community service learning activities are intended to reinforce classroom content while also providing a beneficial service to the community (Bringle \& Hatcher, 1996; Chupp \& Joseph, 2010; McCarthy \& Tucker, 1999).

Strand et al. define community-based research as, "a partnership of students, faculty, and community members who collaboratively engage in research with the purpose of solving pressing community problems or effecting social change” (2003, p. 3). When this involves students working on research projects defined by community partners but for course credit, it is sometimes defined under the umbrella of community service learning (Andrée, 2007).

Participatory Action Research is "a process of producing new knowledge by systematic inquiry with the collaboration of those affected by the issues being studied, for the purposes of education and taking action or effecting social change” (Macaulay et al., 1999). Participatory Action Research does not necessarily involve students, but it is typically rooted in collaboration among academic and non-academic partners in research.

While there are important distinctions between each of these forms of communitycampus engagement, including whether they are teaching or research oriented, our focus is on their common element: the relationship between community-based organizations and colleges or universities, often mediated by specific faculty members and community organization representatives. This paper therefore discusses community-campus engagement in general terms throughout, while noting where some of our case studies were concerned with specific forms of this engagement in teaching or research.

A number of benefits have been identified for the various forms of community-campus engagement. For community-based research and participatory action research, these include grounding academic research in real-world context (Chopyak \& Levesque, 2002). For community service learning, benefits include strengthening student skill levels, work skills development, and leadership capacity (Chupp \& Joseph, 2010; Kozeracki, 200l; Tucker \& McCarthy, 1998). For community organizations, it is argued that such partnerships provide them with services for free when many are constrained financially, thereby helping them to be more effective and efficient (Andrée, 2007; Chupp \& Joseph, 2010). It is notable, however, that the literature on the impacts of community-campus engagement often treats the community solely as a beneficiary rather than as a partner in identifying the problems and solutions (Ward \& WolfWendel, 2000). Ward and Wolf-Wendel (2000) argue that this blind spot is rooted in the way these projects, and especially community service learning, are framed as ways for higher education to do for the community rather than as a way to do with the community. These critiques suggest the need for approaches that allow students and faculty members to work alongside other community members to address issues as 'insiders' rather than as 'outsiders.'

To realign community-campus engagement in this direction would require addressing a number of additional barriers and challenges. Since community organizations and universities are structured and organized differently, institutional and structural issues can affect the development of a truly equitable relationship. Such issues include the allocation of funding, decisions on teaching and research mandates, and determinations of what constitutes valuable knowledge and outcomes. For example, community organizations often feel that students' educational needs or faculty publication needs come first, and that the community must fit their 
needs into a predesigned package. These concerns can result in conflicts over research priorities (Stoecker, 2008). Sullivan et al. (2001) also identify trust issues that act as barriers, including: a historical lack of trust between communities and academic institutions; awareness of past mistreatment of the communities in academic research; and the concern that academics may be dishonest about their research agendas.

In response to these challenges, new approaches to community-campus engagement are emerging. Swords and Kiely (2010) call on community service learning to be reinvented with more emphasis in areas such as organizational learning and community development. Stoecker et al. (2009), drawing on extensive interviews with community partners in service learning, propose a model of course-based community-based research - in place of most other forms of community service learning - that is carefully designed to achieve the research outcomes set out by the community partners. At the level of practice, the US-based non-profit organization CommunityCampus Partnerships for Health is developing a progressive partnership approach among communities and academic institutions in order to achieve health equity and social justice. ${ }^{4}$

Community-Campus Partnerships for Health seeks to challenge some of the problematic institutional structures, including how academic research is defined and evaluated by university tenure and promotion committees. Nelson et al. (2005) are among Canadian academics at the forefront of change. Their article outlines a 'recipe’ for community-academic partnerships to help address some of the general challenges around community-campus engagement, including the need for collaboration founded in trust and a shared vision for moving forward. Nelson et al. (2005) draw on the concept of contextual fluidity from complex adaptive systems theory, as well as community development theory, to flesh out the practices of effective engagement.

Complex adaptive systems theory offers an entry point into this work because each participant in community-university collaborations is a complex system in its own right. When these complex systems interact they mutually shape each other's evolution (Stroink \& Nelson, 2013); these interactions are not always linear and predictable. All engaging communities, whether they are universities and colleges or social benefit organizations, have their own goals and reward structures, timelines and ways of doing business. Through their interactions, many behaviours and outcomes emerge that could not be predicted by the individual actions of each part of the collaboration. The contextual fluidity literature encourages actors to recognize that (1) often a specific project is as much about the intersection of webs of networks as its declared goals; (2) there may be no centre outside of shared context and especially the shared vision; (3) fluidity - in outcomes, direction, timing — can be a strength; and finally (4) formal and informal linkages, planned and unplanned, conscious and unconscious interactions, are all importantpossibly critical - to the final results.

Nelson et al. (2005) also draw on the community development literature in their recipe. Campus-community engagement to meet shared goals is ultimately about community development in a number of ways (Stoecker et al., 2009). The lessons of how to engage in effective community capacity building thus become important tools for collaboration (Block, 2010; Born, 2012). There is some overlap between these tools and those necessary to work in complex adaptive systems. To the latter, community capacity building practices add: the importance of participation in the process; developing a keen ear for listening to all community voices; focusing on strengths not problems; being opportunistic in using available —and

\footnotetext{
${ }^{4}$ CCPH website: https://ccph.memberclicks.net/
} 
diverse - resources; finding ways to respect and bring out the unique skills_—or gifts_-of individuals and groups; putting more energy into the process than into definitive plans; accepting and building from mistakes; and engaging all (Nelson \& McPherson 2004; Nelson, Stadey \& Lyons, 2005).

This review of the literature on community-campus engagement illustrates a number of challenges inherent in this approach to teaching and research, while also pointing to a new generation of better practices. The four case studies presented below move this conversation forward. They highlight the internal complexity of both 'the academy' and 'the community' and suggest that finding common ground for a respectful research relationship is akin to crosscultural dialogue. They underscore the need for flexibility and an honest examination of differences in power. They also point to specific constraints imposed by funders.

The following reports are quite different from one another. Our research approach was grounded in the needs of our collaborators, both academic and community-based. Each project's collaborators wrote the case study reports and then worked with the CFS hub co-leads (Cathleen Kneen and Peter Andrée) on this paper. In some cases, the case study research was on the process of community-engagement itself and in others reflections on engagement emerged in the context of evaluations of community service learning and community-based research projects with independent aims. Our first case examines two models of community-campus engagement in Waterloo, while the second presents reflections on a research project that involved a class of community service learning students in Thunder Bay. Our third case study is a new communitybased research project undertaken by two partnering organizations based in Toronto brought together by the hub. The fourth reports on the results of a community-based research project led by a network of activists in BC who interviewed food system change leaders and experienced community organizers, primarily from Indigenous communities, about what they had learned about effective collaboration, not just between campuses and communities, but also across cultures and worldviews.

\section{Case Study 1: Community-campus engagement in the Waterloo Region Food System ${ }^{5}$}

Our first case studied the effectiveness of two ad hoc models for including students in efforts to create a healthy community food system in Waterloo Region in southwestern Ontario. Waterloo Region includes three urban centres and four rural townships with a population of 560,000. One of the two models under study is an inter-disciplinary practicum program in the Healthy Eating and Active Communities Team (HEAC Team) at Region of Waterloo Public Health. The second involves a series of research projects completed by students in a fourth year food systems course at the University of Waterloo for use by community-based partners.

These two models differ in how they are initiated and how they operate. In the HEAC Team model, rather than a university professor or a university-based broker connecting students with a community partner, the Team acts as both host and intermediary. It gathers students from many different universities and disciplines and deploys them to directly or indirectly support the work of a number of civil society organizations in the region. The University of Waterloo model represents another variant of community-based research, providing research to a range of civil society organizations, as opposed to specific community partners.

\footnotetext{
${ }^{5}$ This case study prepared by Katherine Pigott, Steffanie Scott and Wajma Qaderi-Attayi
} 


\section{Model 1: The HEAC team}

Region of Waterloo Public Health recognizes food as a key determinant of health due to its ability to influence the physical well-being of residents, improve the environment, stimulate economic growth, preserve the vitality of rural communities, and build a sense of social connection. Nasr and Komisar (2012) describe their collaborative activities and research on food system planning as "exemplary" and "cutting edge” (p. 50). Within Region of Waterloo Public Health, the Healthy Eating and Active Communities Team, led by Katherine Pigott, has been a facilitator of a healthy community food system since 2000. Programs and initiatives are tailored to respond to community needs as per the 2008 Ontario Public Health Standards.

From 2000 to July 2013, the HEAC Team has hosted 57 students from a variety of academic disciplines to support the HEAC Team's activities. Practicum students are from a variety of universities and colleges in Southern Ontario. The positions are predominantly unpaid, except for graduate student planner positions. Students' length of placement and learning objectives vary according to discipline and academic institution. The HEAC Team guides the work of students and links students to the community partners with which it collaborates. Some student practicums support research and evaluation based activities in a variant of communitybased research. For example, a graduate student planner and a public health nutritionist practicum carried out interviews with community members as part of the Community Garden Storytelling project that measured the community health outcomes of community gardens in Waterloo Region. Other practicum projects are a variant of community service learning as students are directly engaged in developing and implementing healthy food systems initiatives with community partners. For example, a master's of social work student helped to convene community meetings to plan and develop accessible gardens in four neighbourhoods, and a community psychology student implemented a recruitment strategy to find volunteer bloggers to ensure current content on the Waterloo Region Food System Roundtable website.

\section{Model 2: University of Waterloo}

In the second model, the Department of Geography \& Environmental Management at the University of Waterloo offers a one-term fourth year undergraduate course on Food Systems and Sustainability that attracts $40-50$ students each year. It examines food system sustainability and food security from production to consumption, from local to global, strongly emphasizing civil society initiatives and the localization of food systems. This course, taught by Steffanie Scott in 2010 and 2011, offers community-based research opportunities to students working in groups of three or four. As a result of Steffanie's membership on the Waterloo Region Food System Roundtable ${ }^{6}$ since 2007, she has been able to solicit ideas for potential student research projects from fellow Roundtable members, among other contacts. These projects dealt with a range of issues, including stakeholder perceptions of community supported agriculture in the Waterloo Region; compensating farmers for ecosystem services; barriers and opportunities faced by homesteaders raising urban livestock; and barriers to the use of emergency food programs by low

\footnotetext{
${ }^{6}$ The Roundtable serves as "a networking and policy-making group working on building a strong voice for a healthy food system in Waterloo Region.” (WRFSR, 2013). Its members include local farmers; emergency food providers; food processing, distributing, and retail business people; health professionals; and academics.
} 
income populations in Waterloo Region. Most research projects do not directly benefit a single community organization - other than the Roundtable by enhancing the evidence base around its six priority areas. Nor were the final papers necessarily fed back to any community organizations other than the Roundtable, though a few were.

\section{Methods}

Wajma Qaderi-Attayi was hired as graduate student planner and worked in the HEAC Team from January through July 2013. She carried out data collection and analysis and communicated research results along with Katherine Pigott and Steffanie Scott. Thirty-one participants - two lead researchers, 11 University of Waterloo students, 10 Public Health placement students, six Public Health staff, and two community-based partners-were interviewed by phone or in focus groups. All sessions were recorded and later transcribed. Data was analyzed using N-Vivo, a qualitative software tool, to collate preliminary findings.

\section{Findings}

A common challenge identified for both models related to institutional protocols. Healthy Eating and Active Communities (HEAC) staff noted that significant financial and staff resources go towards the support of student placements. Furthermore, there is a strong and growing demand from universities to take on practicum placement students but without financial compensation to host organizations, and sometimes with limited involvement of universities as the practicum placement unfolds. Another administrative challenge relates to the varying length of placements and number of hours that are required each week, and in general both students and their supervisors - Region of Waterloo Public Health staff-felt that longer placements were more beneficial. Many of Steffanie's University of Waterloo students also reported difficulty finding or connecting with appropriate stakeholders within the assigned timeframe to gather information for their research projects (i.e., one semester).

On the other hand, a real strength was the centrality of symbiotic relationships in each model. There are many informal relationships at the heart of these student placements and research projects. To enable this, there appears to be an undefined, and even unspoken, acceptance whereby universities, community organizations, and students have depended on one another's abilities and skills to advance projects, tasks, and/or partnerships. None of these actors are obliged to form these partnerships; the collaboration emerges because of shared goals and interests in relation to the creation of a healthy community food system. For example, the HEAC team and Opportunities Waterloo Region—a non-profit—worked together on various projects: a neighbourhood market pilot project, a community garden capacity building project, an ethnocultural outreach project, and an accessible garden project. In many instances, they enlisted the support of practicum students to move the work forward. The creation of this system of mutual interdependence has worked well, leading to opportunities that would have not existed otherwise. This symbiosis was even found in the intersection between HEAC and the work of Steffanie Scott's students, as revealed in this quote from a public health staff-person: 
Sometimes these papers from 4th year students... [were] really useful and really helpful piece of work which was a bit of a surprise! It was very useful and applicable work that we wouldn't/couldn't have done otherwise... Some of the projects we had no role in determining but they still were very helpful (Interview 1$)^{7}$.

Finally, research on both models led to a related set of suggestions. First, more attention needs to be given to aligning students' learning objectives and skills with those of the assigned project to lead to a more successful placement and project completion. As one HEAC staff person noted in an interview:

Sometimes there is a mismatch in skills brought in, compared to what you as an organization require of them-usually again this doesn't happen as we have interviews and selection criteria but sometimes it does happen. [We try and be mindful] to triangulate and align three goals: meet the students' needs, colleges'/ universities' requirements and also trying to complete the work [for the community partner] (Interview 2).

It would also be beneficial to have clearer brokerage roles established for students, universities, and hosting organizations - in the case of student practicums on the HEAC Team - that specifically match skills, projects, and learning objectives. For their part, the hosting community organization should identify clear objectives, and university programs should clearly outline their learning goals. For the course-based projects, the data suggested that the instructor could dedicate more time to discussing the principles of experiential learning and community engagement as context for the students’ research projects.

\section{Case Study 2: A workforce multiplier study of locally produced and processed foods in Northwestern Ontario ${ }^{8}$}

Our second case involved a study of the workforce multiplier effect of the agricultural and food processing sector in Northwestern Ontario. It was undertaken as a form of community-based research by a class of third year university students at Lakehead University.

The study emerged out of an initial encounter at a Thunder Bay food strategy meeting between Steven Bill of the North Superior Workforce Planning Board and Connie Nelson of the Food Security Research Network based at Lakehead University. Later, the Workforce Planning Board invited their sister organization—Northwest Training and Adjustment Board—-to join. ${ }^{9}$ Expanding the group allowed them to study all of Northwestern Ontario, which is the geographic focus for the FSRN.

\footnotetext{
${ }^{7}$ In order to standardize our way of reporting in this paper, which is based on a large number of interviews from four different case studies, those interviewees directly cited were given a number from 1 to 17 .

${ }^{8}$ This case study prepared by Connie Nelson and Mirella Stroink

${ }^{9}$ The Workforce Planning Board represents the District of Thunder Bay and the Training and Adjustment Board represents the Districts of Rainy River and Kenora.
} 


\section{Methods}

Data to determine the workforce multiplier effect was collected through individual interviews, three focus groups - one from each district - and surveys conducted by Lakehead University students in the Faculty of Natural Resources Management as part of a community service learning experience in a Forest Economics course taught by Dr. Chander Shahi. The survey data was compiled and compared with the secondary data obtained from Statistics Canada, and the current and projected number of jobs related to the local farms and food processors were estimated. The number of direct and indirect jobs for each district was estimated by prorating the Gross Domestic Product (GDP) from the provincial data, obtained from the Conference Board of Canada. GDP projections from 2013 to 2017 for crop and animal production in Ontario were used to predict the number of direct and indirect jobs related to local farms and food processing businesses in the region.

\section{Findings}

The food production sector in Northwestern Ontario has a workforce multiplier effect of 1.4. (Thunder Bay District 1.7, Rainy River District 1.3 and Kenora District 1.2). This means that every 1000 jobs at local farms and food processors support 400 additional jobs indirectly among suppliers and retailers. This analysis also shows a preliminary finding that Northwestern Ontario has a higher rate of farm capital market value supporting jobs as compared to the provincial average. The density of the networking in Northwestern Ontario appears to provide more local sector food opportunities at a much lower investment cost than the provincial average. ${ }^{10}$

\section{Reflections on the process}

To understand the success of this joint engagement in research among university students, professors associated with the Food Security Research Network, and two workforce planning boards in Northwestern Ontario, it is important to examine more deeply the evolution of the "incommunity" (Harrison, Nelson, \& Stroink, 2013) engagement at the basis of the relationship.

After that initial conversation between Steven and Connie, some shared interests began to emerge. Several dynamic and informal discussions eventually led to a merging of relevant and complementary skill sets: the Workforce Planning Board had expertise in workforce planning and an emerging interest in food, but no data; FSRN had experience in local food system issues, but had never previously considered workforce questions.

Early in the process, Steven wrote a concept paper explaining the rationale for a workforce multiplier study to "assist in strategically directing future initiatives that address food security and agricultural development within Northwestern Ontario” (Bill, 2012). This paper provided a focus for subsequent discussions.

Funding was a key concern. Early on, the Workforce Planning Board had identified that they could put forward $\$ 5,000$ as matching funds for this project. Likewise, FSRN had a promise of \$5,000 through CFICE toward this case study. However, both organizations knew from

\footnotetext{
${ }^{10}$ For details see http://www.fsrn.ca/
} 
experience that undertaking a study of the multiplier work force for the vast geographic area of North-western Ontario through community-based focus groups would normally cost $\$ 100,000$ or more.

FSRN then suggested the option of a community service learning approach, effectively training students while garnering research results along the way. This approach was an unknown to the Workforce Planning Board, but they quickly became interested. Using the NSWPB concept paper, the FSRN approached Dr. Shahi, who taught food security issues in his forest economics class. Dr. Shahi's students came onboard. Meanwhile, the Workforce Planning Board approached the Training and Adjustment Board for another \$2,500 in funding. As the group could not expect students to pay upfront costs and then get reimbursed, some immediate funding was essential. The Workforce Planning Board wrote a cheque to FSRN within two weeks of making the decision to proceed, in order to cover transportation and accommodations for students to meet with focus groups of community members in all three vast districts of Northwestern Ontario. This quick turnaround demonstrates the trust that had developed in the FSRN, Workforce Planning Board and Training and Adjustment Board relationships.

The groups involved are now looking to the next steps. All of the organizations agreed that the workforce multiplier work had successfully developed a new economic tool for Northwestern Ontario to gauge the role that agriculture has on the northern economy, and are now looking at moving forward on a range of regionally-focused projects that emerged during the community-based focus groups. ${ }^{11}$

\section{Case Study 3: A collaborative study of student-based campus food systems initiatives ${ }^{12}$}

Our third case study involves a community-based research project undertaken as a result of a new partnership between Meal Exchange and Ryerson University’s Centre for Studies in Food Security. Meal Exchange is a national registered charity that was started in 1993 at Wilfrid Laurier University. Today it works with students on over 60 campuses to achieve its mission of engaging, educating, and mobilizing youth to work with their communities in order to alleviate hunger locally and achieve food security. Established at Ryerson University in 1994, the Centre for Studies in Food Security promotes food security through research, dissemination, education, community action, and professional practice. The Centre takes an interdisciplinary and systemic approach to the social justice, environmental sustainability, health and socio-cultural aspects of food security.

Initially, the joint Ryerson/Meal Exchange case study was to focus on re-launching an online student-led peer reviewed academic journal. However, over the course of six months of conversations among the case study partners and the co-leads of the CFS Hub, the focus shifted considerably. Louisa Hawkins, a Ryerson University student who was in the last year of her undergraduate degree, was eventually funded through CFICE to analyze student-led food systems initiatives on Canadian campuses on behalf of Meal Exchange. The purpose of this study was to understand how student-led alternative food systems initiatives (especially farmers markets and food gardens) on campuses get started, how they are maintained, and on the role of

\footnotetext{
11 To see the key actors in this work discussing their community-engagement process in a webinar for CFICE, go to http://foodsecurecanada.org/community-networks/community-academic-collaborative

12 This case study was prepared by Louisa Hawkins, Christina Muehlberger and Peter Andrée
} 
community partnerships in the process. Because of this study's focus on student-led communitycampus engagement, both the research results and the community-based research process are discussed in the cross-case analysis section that follows.

\section{Methods}

Data for this study were collected through eight qualitative interviews with student leaders directly involved in the initiatives. The analysis involved describing the six campus food systems' initiatives: gardens at Ryerson University, the University of Toronto and Vancouver Island University Nanaimo Campus; and farmers' markets at Simon Fraser University, McGill University, and the University of Northern British Columbia. We drew themes from the interview data in order to answer the research questions, at least from the student leaders' perspectives. Due to the limited number of interviews, the findings of this study are considered preliminary. However, they offer a useful entry point into further research on student-led initiatives. The interviews also corroborated some of the main points previously identified in the literature on community-campus engagement.

\section{Findings}

Highlights from this case study include the importance of communication, accommodation of partner needs, community-building, institutional buy-in, and approaching the initiative in a business-like manner.

Communication with both community partners and team members was of great importance across campus initiatives. A student leader from one of the markets commented:

It's important to have meetings in person when you can talk to all the vendors I think...they don't necessarily use email the same way that students do...so sometimes it takes a little more legwork to phone them or go to the downtown market on Saturday and talk to them there in person (Interview 3).

In addition to maintaining good relationships with market vendors, students who run weekly markets must also maintain good working relationships with other initiative partners — such as campus parking and loading dock staff_-and find out what their needs are, as another student leader explained:

Finding out what would work for them and what wouldn't work for them... we had to change our market hours to make sure that we closed early enough to be able to have the vendors leave off the loading docks before [campus staff] was supposed to leave for the day because to ask them to stay late every single Tuesday was just a little bit too much (Interview 4).

This example highlights the need for appropriate accommodation for community partners, which was commonly cited in the interviews as key for the success of these initiatives. 
Community-building through education and knowledge sharing was also widely recognized as being a driving force behind the success of campus food projects. Food related workshops seem to be a popular method of promoting campus initiatives while spreading knowledge about food growing and preparing.

For long-term success, institutional buy-in was also identified as critical. One student project leader, when asked about the longevity and success of their garden project, said "it's so integrated into our department now...the department really uses it as a bit of a bragging tool" (Interview 5). And how can students garner institutional buy-in? Another project leader asserted: "You have to plan out, you have to have the right connections...it's a really big project...it needs organization...seriousness as well, just in order to get accepted by the university" (Interview 6).

Many interviewees summarized these ideas in terms of the need to approach their initiatives 'as though they were a business.' Project leaders emphasized that the initiatives were fuelled by passion for good food and alternative food systems, but their experience had also taught them that without proper attention towards funding, balancing their budget, and maintaining detailed records, their projects would not be as successful as they could be.

\section{Reflections on the process}

Notwithstanding the valuable stories and insights that were gathered through this research, this case study faced a number of challenges along the way. First, the faculty member who initiated the case became unavailable, and then a second faculty member had to remove herself from the work due to a potential conflict of interest. When a third faculty member was able to provide useful methodological advice, a number of months had already passed. The next challenge was that student leaders' attempts to recruit faculty and administrators at their respective institutions did not result in any interviews. After several more months, a new research protocol was developed and submitted to the Research Ethics Board at Ryerson for approval. Despite the implementation of this new protocol, interviews with faculty members and administrators remained elusive. In the end, Meal Exchange staff believe that they learned from the process of collaborating with a university, particularly with regard to research methodology, and the research ethics process. Furthermore, the full case study report ${ }^{13}$ contains a number of recommendations on how to approach this type of project differently in the future.

\section{Case Study 4: Building and maintaining inclusive food security networks to support Indigenous and Non-Indigenous communities ${ }^{14}$}

Our fourth case study was undertaken by the BC Food Systems Network (BCFSN). This volunteer-run network formed in 1999 to link people across BC on community-level action related to food. BCFSN is comprised of a diverse group of people involved in food systems work, including: community health workers, farmers/gardeners, Indigenous food sovereignty leaders, traditional harvesters, academics and researchers, civil society organizations, political advocates, and others. The network has approximately 300 members and hosts 19 listservs supporting regional communication and connecting people on specific topics across the province.

\footnotetext{
13 The detailed report can be found at studentfood.ca

14 This case study prepared by Dayna Chapman and Wanda Martin
} 
The network holds a strong belief in having grassroots and marginalized groups involved in the process of policy formation at all levels. BCFSN is closely connected to the work of Food Secure Canada and through that relationship became involved with the CFS hub.

This case study was premised on the fact that Indigenous people occupy a delicate and critical space in relation to food security and food systems research, yet far too often such research has been rejected by Indigenous communities as disrespectful of their culture or even downright exploitive. In the land we call 'British Columbia,' cross-cultural dialogue has been embraced by the BCFSN through hosting the Indigenous Food Sovereignty Network and developing relationships with the Vancouver Island and Coastal Communities Indigenous Food Network, as well as various academic institutions around the province. In the past decade, Indigenous leaders-including the Indigenous Food Sovereignty Network—have started several initiatives to develop guidelines and protocols for engagement in food systems research, and this work continues. This case study, undertaken as a Participatory Action Research project, built on that work and the successful models of cross-cultural dialogue and relationships within the BCFSN. Its purpose was to shed more light on the complexities of those relationships and best practices that could inform future research relationships in and with Indigenous communities. To that end, the study engaged leaders in the BCFSN—including members affiliated with a provincial academic institution — as well as Indigenous leaders and traditional knowledge holders and users.

\section{Methods}

The interviews for this case study were undertaken by Dayna Chapman, at the time a Board member of the BCFSN, who lives in a Nuxalk Nation community. The fact that she had a relationship with many of those whom she interviewed meant answers came from conversations grounded in trust and respect. To broaden the scope, the research team also hosted two exploratory sessions on the subject of cross-cultural collaboration at the Food Secure Canada Assembly in Edmonton in the fall, 2012, and a session on cross-cultural relationship building during the BCFSN's annual Gathering in July 2013. Researchers analyzed data using constant comparative methods.

\section{Findings}

All interview participants agreed that it is important to engage cross-culturally. Participants noted that living together on common land means that they do not actually feel they have a choice about engaging cross-culturally, it is part of what they do. They also felt that food issues, in particular, create a bridge and provide a common framework for looking at multiple issues, such as land, health, and governance. Food is also useful for addressing social injustices and the legacies of colonization. As one person noted, "the work of decolonization is our common work" because colonization has negatively impacted 'settlers', although to a much lesser degree than Indigenous people.

Engagement and collaboration need to occur as an equal relationship where all cultures come together with no agenda except to build relationships and to learn from each other. 
The key is, it's a relationship. First, getting to know each other, our histories, communities, ways of communicating, stories, listening. An element of 'doing', not 'consultation'. We need less talking, more doing. It sparks energy in relationships and ideas bubble up (Interview 8).

Open communication is needed about a non-commodity approach to food and a deeper understanding of values. Challenging collaborations often result from one partner having a narrow, culturally-myopic, point of view. As one person of Indigenous descent noted,

We don't fit into the existing framework of institutional thinking. It's challenging when we're placed into a category of 'producer', which is neoclassic economic language (Interview 11).

Another interviewee was asked by authorities how to get more fresh vegetables into remote communities. This way of framing the problem reveals a very top-down, simplistic approach, which ignores locally available sources of nutrition other than imported vegetables. Seldom is there appreciation for local knowledge and for engaging communities directly_communities who have successfully fed themselves for centuries. As she noted:

I see people so passionate about things like preserving farmland, which is such a huge battle in itself, but we need to get better at working with Indigenous allies and partners to find solutions that apply to a broader lens. The whole food system is connected (Interview 16).

Indeed, the focus on farmland, while important, sidelines the traditional Indigenous food systems which often included some agriculture but within the context of fishing, hunting, and gathering.

Similarly, as reported by one participant, many non-Indigenous university students approach Indigenous community members with a single-minded agenda. For successful engagement, research needs to be mutually beneficial. This requires the researcher to be involved with the community at an early stage, develop a positive relationship, and mutually identify all stages of the research project, allowing a vested interest and ownership of the project by all involved. The different perspectives and worldviews can then be a complement to research, giving it depth by reflecting values, goals, and community vision. Overall, while collaboration can be difficult, "challenges are where the learning edge is" (Interview 17). It is only by facing and overcoming challenges that understanding develops and genuine relationships build.

All study participants had tools, tactics or strategies for working with cross-cultural partners. The central commonalities among them are: that they remain open and flexible to change; that there is adequate time allowed for developing shared protocols; that they contain a clearly defined and agreed upon purpose; and that they hold a tradition of respectful engagement. In order to develop such an approach, both parties need to know themselves and know how to listen to each other. It is also important to be respectful about what is unknown and seek guidance. As one person said: 
For partnerships, it's good to have an informal agreement acknowledging you're coming from different experiences; it sets a tone of respect. Inquire! Ask! When we don't, that's when we make mistakes. You can’t be afraid to respectfully ask questions. Get the guidance and teaching you need (Interview 8).

Indigenous communities have their own protocols and guidelines and it is important to look to the community rather than impose institutional understandings of community engagement. Also, there is a ceremony piece that may easily be overlooked by non-Indigenous cultures because it is often not practiced in the same way between cultures. As one person noted, "pay attention to the ceremony. It connects us so much more to what we're eating and where we're coming from and who we are together" (Interview 15).

Another common theme was around issues of time. Time is necessary for engagement if it is to be successful:

If something is really a community priority, people will give it the time it needs to do it properly which sometimes means it will happen over a long time. Artificial, imposed timelines can be a problem-people feel like they have no control and they'll leave (Interview 9).

Another participant stated the following:

It's so important, actually having the time and communication with students during the revision process, too, to make sure things aren't getting misinterpreted. It happens easily with different worldviews. Part of the project has to be including adequate time and resources to make sure this happens (Interview 11).

\section{Reflections on the process}

Cross-cultural engagement in the BC context is primarily about decolonization. The BCFSN values cross-cultural engagement because of the opportunities to learn and increase consciousness and awareness of mutual challenges. It can be both challenging and rewarding for non-Indigenous people to remain mindful of the need to work toward decolonization. Respectful listening and honouring of local knowledge are key aspects to successful engagement. This work appears to require a humble approach to learning and working together that allows all those involved to strengthen their ability to respond to challenges in food system redesign.

Before interviews were conducted an application was brought forward to the research ethics board of Carleton University to undertake interviews with individuals from Indigenous communities. Because of a history of exploitative research in many of these same communities, collaborative research guidelines were developed - over several months - between the CFICE project and the BCFSN. These guidelines ensured that the individuals interviewed for this project, as well as members of the BCFSN, retained a high level of control over the research process, interpretation of results, and the sharing of results. 


\section{Methodological insights}

What do these cases tell us about building effective relationships for community-engaged scholarship-whether in the form of community service learning, community-based research, or participatory action research? This section presents our collective reflections. In addition to presenting additional details from the cases, it includes comments recorded at roundtable discussions organized at the Food Secure Canada assembly in Edmonton (November 2012) and the Canadian Association for Food Studies meetings in Victoria (May 2013), where these four cases were presented and analyzed together. Participants in those discussions included case study collaborators as well as a wider group of university and community practitioners working on food issues in Canada. This step in the process was itself consistent with participatory action research and community-based research protocols, which encourage processes that include the research “partners” in the analysis (e.g. van de Sande \& Schwartz, 2011).

\section{Disaggregate 'community'}

Our first task is to interrogate the word community. In a project called "Community First: Impacts of Community Engagement”, we are constantly tempted to make simplistic assumptions about who 'community' is and whose priorities we put 'first.' For example, some within the research project encourage us to look to those groups most vulnerable, and make the case that even the civil society organizations which purport to speak for many members of the 'community' may represent a level of bureaucracy that can get in the way of understanding what community members really think, feel and need. Recognizing that power is at play is always a valuable starting point, but this particular viewpoint has its limitations.

We have come to the conclusion that whenever 'community' is invoked, it is important to speak about the specific actors that we are engaged with. For example, there are variations in governance, power, resources and legal status among the civil society organizations involved with the CFS hub. A regional public health department is very different, culturally — both in its organization and in the types of power it has-from an unfunded provincial network of food system activists, from indigenous food sovereignty activists, and from a national non-profit organization that advocates for food security with funding from a major foundation. They all convene or represent 'community' in one way or another, but their variation has led us to recognize the specific needs of each in relation to community-campus engagement.

And of course colleges and universities are also communities in their own right, and themselves members of their local, national and international communities. In keeping with this way of thinking, Nelson and her colleagues encourage us to see academic researchers as community members first (Harrison et al., 2013; Nelson et al., 2005; Nelson \& Stroink, 2012). Academics may bring specific skill sets, and sometimes have access to resources or other forms of power, but this is true for all of the other actors involved in our collaborative activities in one way or another. Each actor also brings his or her own particular 'baggage' that may hamper collaboration.

Given these differences, the ability of communities to engage with one another varies considerably. This needs to be taken into account by practitioners of community-campus engagement, and when differences between collaborating entities are significant, the relationships need to be approached with great care. Further, there are imbalances of power 
within universities, and power dynamics among community organizations, including hierarchies, which are not always transparent to students and faculty members who engage with them, adding additional layers of complexity.

At the Canadian Association for Food Studies conference, discussion on the question of the power dynamics between academic researchers and community organizations was summed up by a non-academic participant as follows:

We should not fetishize community as the purest of the pure. We are all parts of different communities. An academic may have power in the classroom, but outside of that space, is a member of different communities. The privilege and power emerges in the interactions, the dynamics as we communicate with each other, and sometimes we need to be a little bit relaxed about who has power and who has privilege and just listen to each other.... Sometimes we just need to ask "How can I help you? How can you help me? How can we produce something collectively that will add value to ourselves, to our organizations, and to the community at large?” (CAFS Roundtable, 2013).

The metaphor of dancing surfaced as a way to think about these relationships: "This work is like learning to dance with each other. Sometimes we will be stepping on each other's toes and we will say, 'oops, I'm sorry' and learn not to do that” (CAFS Roundtable, 2013).

\section{Establish community first}

Our second insight, then, is about how to establish 'community' among the key collaborators. We define 'community' as a set of relationships based in common experiences, interests, and /or purposes. The process of establishing community must thus involve a shared vision, which becomes the glue for keeping the collaborations moving roughly in the same direction. Further, attention to the vision - rather than the details of a project-allows for emergent, unplanned for and innovative happenings within the larger framework.

This ingredient for success is exemplified in the Northwestern Ontario project. In their report to CFICE on their community service learning experience, Nelson and Stroink write: "Our project did not come first. Rather the project self-organized from the relationships and interests" $(2013,2)$. Establishing these relationships early in the process allowed the collaborators to weather challenges later on. For example, in early dialogue, the Food Security Research Network had convinced the Workforce Planning Board about the need to look beyond the larger producers in the region when doing a workforce multiplier study. This issue came back later in the process. However,

...because of the trust and respect that had been built up among the main players, this potentially contentious issue was handled without a ripple. When the group's inclusion of both emerging and established farm producers was later questioned by one of the local farm organizations, the group was able to handle the question of 
who should be included in a workforce multiplier study in a very positive way because it had already been dealt with internally rather than swept 'under the table' (Nelson \& Stroink, 2013, 3).

It is worth noting that the group's vision was not only shared verbally. It was written down in Steven Bill's initial concept paper (Bill, 2012), and that document underpinned the work as it developed.

The Northwestern Ontario case also provided an interesting example of the role of humor in building community among collaborators. Consider this story relayed by Connie Nelson and Mirella Stroink of the FSRN in Thunder Bay:

I remember early on, we came breathlessly, in order to be on time, to a meeting with Madge and Steven in our market garden attirefield boots, old dirty clothes and unwashed hands and face. Madge looked at us and giggled and said 'welcome' into her warm but very pristine boardroom.... Humour turned out to be one of our ways of reinforcing our humanness (Nelson \& Stroink, 2013, p. 4).

Given that our work in this hub is all about food politics in one way or another, the BCFSN interviews also remind us of the power that sharing food can have in the building of community. As Chapman and Martin note in their project report, "food is a tool for engagement because it is something we can all relate to. It creates a bridge and provides a common framework for looking at multiple issues, such as land, health, and governance” (2013, p. 3).

On the other hand, not taking the time to build collaborative relationships can have significant negative repercussions when it comes to working together. One participant in the $\mathrm{BC}$ research shared the following:

When people come and there are strong agendas and there's no relationship built, we've had meetings come to a complete standstill. We end up having to take time to educate, which was not the point of the meeting (Interview 12).

In the CAFS conference discussions, this point was summed up in the following way by one of the participants:

It is important to share and dwell on the utopian visions of why we are all here, which helps people to identify why we are working together and is something that people can come back to (CAFS Roundtable, 2013).

It is notable that the challenges experienced in the Meal Exchange-Ryerson case study may be linked to the difficulty that the collaborators had in establishing a shared vision from the outset. These organizations had not worked together before, and experienced setbacks in building a working relationship. Then, when the student researcher faced methodological challenges, the 
support structure was not necessarily in place to assist her quickly. Still, that work generated useful insights, including some that reaffirm this very point. For example, the leader of one of the university markets noted the value of building a team that is able to work together:

Finding the right people to take on the project means so much, making sure that the team of people want to work together and that they push each other to do more is very important (Interview 14).

Establishing community first takes time, and this is something activists, working on many fronts, have precious little of, especially when outcomes - such as research reports-are far-off and it is uncertain what the benefits will be. Establishing community may also take money, in order to travel and work together, for example. How do we effectively share resources to do community engaged scholarship well? This remains a question for CFICE. Our experience to date shows that sharing funding from the Social Sciences and Humanities Research Council (SSHRC) with civil society organizations to help manage the hub, and to undertake these case studies, can be very challenging. SSHRC has many mandatory protocols, from the need to prepare an academic CV to be part of the project, to requiring the civil society organization to track in-kind contributions with meticulous detail. University-based processes can also mean that actually getting the funding to the organization can take many months longer than it should. All of these factors make it difficult for civil society organizations to engage in a university-based process on an equal footing with their academic collaborators.

\section{Negotiate a mutually-beneficial project}

Our third insight concerns the establishment of mutually beneficial directions for the research or teaching engagement. The BCFSN interviews reveal the importance of clearly negotiating a shared project direction. ${ }^{15}$ Those interviews also bring to the fore the role of culture, and the potential need to bridge different understandings, such as neoclassical economic understandings of land use versus Indigenous perspectives. This work takes time, and that time must be planned for. In Northwestern Ontario, the team clearly put in the time and effort necessary to arrange a research/teaching project, as well as a plan for how to approach it in a manner that worked for all parties and with available resources. The results of the Waterloo research further underscore the importance of getting the right match between capacities and needs, and taking into account what each participant has to offer.

The idea of identifying a shared project that matches goals and capacities sounds simple, but can be difficult to put into practice, especially when trying to accommodate multiple needs and processes. For example, one organizational collaborator may have requirements that dictate how time on a project is spent. At Region of Waterloo Public Health, the HEAC practicum students receive mandatory training. In the interviews, the students, organizational partners, and regional staff all noted the relevance of the training provided (i.e., training in Workplace Hazardous Materials Information System, Region of Waterloo document management and

\footnotetext{
${ }^{15}$ We use the term 'negotiate' not to emphasize that the relationship may be adversarial, but rather to highlight the importance of having both parties interests and needs define the path forward. 'Arranging' a mutually-beneficial project might be a gentler way of phrasing this activity.
} 
Microsoft Outlook, as well as Regional Orientations), but when placements are short, this training can take up a significant proportion of the student's time. Mandatory administrative processes, including paperwork and approvals, were also noted as a challenge by some staff as well as students. Similar issues have arisen in the context of the CFICE projects with regard to the research ethics processes that all Canadian university research involving human subjects must go through.

Beyond negotiating among the existing needs and goals of the collaborators on a project lie deeper questions about what these collaborators' needs and goals should be. Some student placements are paid, for example, while others are unpaid, and there is a trend towards more of the latter. Do more unpaid work experiences serve the student best? At what point is an unpaid internship exploitative?

There are a number of tools that can be used to help these types of arrangements along. These include contract templates and data-sharing agreements. In the case of the BCFSN case study, research guidelines were drafted that would allow the BCFSN to retain a high level of control over how that research would be shared in outputs, including this very paper. Those guidelines included the following clause:

The analysis of the data gathered through interviews will be undertaken by the research team. This analysis will be shared with the Research Committee of the BCFSN to get their insights into data interpretation, and to ensure that data has not been misinterpreted. The final analysis will be developed cooperatively between the researchers and the Research Committee. Once a final draft of the report has been read, and no later than six months after it has been submitted to them, the Research Committee will be asked to determine any restrictions on the way that the data and analysis are to be used, including through conference presentations, and publications (BCFSN/CFICE, 2013, p. 23).

Given the history of inappropriate use of Indigenous knowledge by many researchers, this clause was intended to ensure that the outputs of this research stay true to the intent of the interviewees who participated in the work (through their representation on the Research Committee of the BCFSN). The clause was also designed to ensure that once an agreed upon interpretation of results had been achieved, the researchers would be able to share those results into the future without having to seek further permission from the BCFSN or the interviewees.

Notwithstanding the progress made with this case, it is worth recognizing that the guidelines developed in this project are just one step forward, and that they remain 'academic' in many ways. Within CFICE, we will continue exploring new models for sharing power and control of the data among researchers and community participants as a decolonizing methodology (e.g. Smith, 1999). We plan to draw, in particular, on the growing body of literature regarding Ownership, Control, Access and Possession of data in the context of the history of colonial research practices on First Nations (e.g. Schnarch, 2004). ${ }^{16}$

\footnotetext{
${ }^{16}$ We wish to thank an anonymous reviewer for bringing OCAP to our attention.
} 
At the heart of the idea of establishing a shared and negotiated project direction is a specific epistemological stance which acknowledges that a variety of different forms of knowledge exist, that they each have equal contributions to make to our collective understanding of the world, and that it is critical to establish dialogue among various forms of knowledge. It is only when collaborators accept the equal value of different forms of knowledge and experience that they can come together as equals to truly negotiate the myriad issues that need to be dealt with in a new collaborative research or teaching project.

To better understand this stance, we draw on the experience of one of the CFS hub's partner organizations, Nova Scotia's FoodARC (Food Action Research Centre). It brings a "ways of knowing” (Bryant, 2002) framework to participatory action research practice in Canada. This approach explicitly values and seeks to integrate three types of knowledgeinstrumental, interactive, and critical. Bryant refers to "instrumental knowledge" as that which is “usually created by experts and systematically developed through 'scientific' methods” whereas interactive knowledge is derived from "lived experience acquired through dialogue and information sharing among members of a community” (2002, p. 92). Critical knowledge "considers questions of right and wrong, analyzes existing social conditions, and outlines what can be done to alter social conditions to improve quality of life." It is this same epistemological approach, we argue, which must underpin the development of any new project's direction.

Finally, our cases appear to back the direction proposed by Stoecker et al. (2009) for the future of community service learning. Given a history of poorly executed service learning that drains more from community organizations than it offers in return, they argue that the future of community service learning lies in a community-based research model grounded in community needs and developed through a community development model (Stoecker et al., 2009, p. 190). When we began to define our hub's projects, it was community-based research projects that came to the fore in two of our four projects (cases 2 and 3). A third (Waterloo) involved the study of two different models of community-based research. Finally, the BCFSN project was itself a type of participatory action research that allowed activists to interrogate the forms of cross-cultural engagement-not just community-campus - that was most productive in the context of work on Indigenous food sovereignty. This project orientation gives a strong indication that the needs of Canadian civil society organizations working in the food movement lie in furthering effective relationships with campuses focused on negotiating more communitybased or participatory action research projects in particular.

\section{Cultivate fluidity in relation to context}

As a fourth insight, our case studies provide several examples that reaffirm the value of seeing community-campus engagement through the lens of contextual fluidity, as outlined by Nelson et al. (2005). In the Waterloo case study, it is the vision for a healthy and sustainable food systemheld by Steffanie, Katherine, community partners with which the Healthy Eating and Active Communities Team collaborates, and others involved with the Roundtable-which lies at the centre of the work. Further, it is the strength of that shared vision which allows the symbiosis discussed in the case study, so all of the students, public health staff, and affiliated community organizations can benefit from each other's work while moving in the same direction. 
The Northwestern Ontario case also affirms the principle of contextual fluidity that states that projects bring networks into contact, and that these intersections can be as important as achieving the substantive goals of the specific project:

As our engagement continued, we discovered that both North Superior Workforce Planning Board and the Food Security Research Network are themselves dense and diverse networks... These dense networks of both NSWPB and FSRN mean that we have very quickly become intertwined where projects such as the Multiplier Work Force case study emerge through ripple effects and shared interests across these networks (Nelson \& Stroink, 2013, p. 4).

However, while contextual fluidity may offer insights into how the world really works, institutions are rarely designed to be fluid. In the case of the Northwestern Ontario case study, the research group was challenged by the university bureaucracy, which wanted to see a contract with North Superior Workforce Planning Board and the Northwest Training and Adjustment Board and proof that the CFICE funding would indeed arrive. Such "bureaucratic demands can be issues where a more fluid 'in community' approach is adopted and often takes some creativity to resolve” (Nelson \& Stroink, 2013, p. 4).

Finally, one of the BCFSN interviews illustrated the importance of informal connections in building the cross-cultural relationships necessary to tackle larger issues together. In this case, the informal activity was cooking, and its importance was described in this way:

You just make it happen. You've done it so often. You just need to make it work. So many people were able to jump in and understand. The preparation of the feast became a common equalizer. Working collectively, hands in motion and creating together. It provides hands-on, measurable success that clears the path for relationship bonds to form... being able to do hands-on work together (Interview 17).

\section{Nurture the capacity to engage}

Both Stoecker et al. (2009) and Nelson et al. (2005) emphasize the practical skill set that academics and community members alike must develop when involved in community-campus engagement, and our fifth and final insight reaffirms this. This approach to teaching and research is, at its heart, about building communities of practice among diverse actors. Each of our case studies reaffirms this view in one way or another. A community development approach was evident in the example of the student leaders who recognized that they needed to make an extra effort to reach out to market vendors and university staff on their own terms. It was also clearly named in the BCFSN work by both the Indigenous and non-Indigenous food system activists who decided to place community building and cross-cultural learning at the focus of their case study. 
One of the principles of good community capacity building work is to be opportunistic in using diverse resources. For example, the Northwestern Ontario project brought the community service learning model to the table as a way to make possible a study that would otherwise have cost $\$ 100,000$. That approach also gave a dozen university students the opportunity to experience community-based issues and to undertake primary research. In Waterloo, both models of community-campus engagement also reveal ways of using just a few resources to maximum effect through multiple synergies. The Meal Exchange-Ryerson interviews further back this point. On moving their campus-based food initiative forward, one student leader said:

Be as inclusive as possible...try to incorporate as many different resources that already exist on campus and building positive working relationships for them because it definitely can't be one person's pet project, it needs to be a huge buy-in from the entire community (Interview 4).

\section{Conclusions}

This paper speaks to a number of challenges associated with community-engaged teaching and learning and seeks to help chart a new path forward. Among the challenges that we as practitioners, whether academic or community-based, need to address in building effective relationships include the power imbalances in community-campus engagement, simplistic assumptions about who the 'community' is, student placements embedded in a charity model, and the challenge of sharing scarce resources equitably so that all actors' needs are met. The insights we have drawn here add depth and nuance to the conversations on community engaged scholarship, and suggest guidelines for future practice. These guidelines would encourage practitioners (1) to carefully consider the needs and assets of all of the actors involved, remaining sensitive to the different cultures coming to the process; (2) to establish relationships around a shared vision first, and then (3) to negotiate teaching or research projects that are mutually beneficial; (4) to approach the work through the frame of contextual fluidity, which means seeing the relationships and the vision, rather than the project, at the heart of the work, and remaining flexible and open to emergent opportunities; and (5) to embrace a community capacity building model in working with collaborators to realize a shared vision.

This research has also identified additional areas where work is needed. We still need more study comparing models of community/campus relationship brokering undertaken by third parties (like the Region of Waterloo Public Health as well as university-based community engagement brokers), and clarifying how best to practice cross-cultural community- campus engagement. Recognizing the challenges reported by community partners, we see the need for evaluation of the impact of engagement in communities, including the full costs and benefits, and seeking ways to share research resources without putting additional burdens on civil society organizations. Further research must also involve an examination of ways to streamline all of the administrative aspects of such projects, including the university ethics processes. On the other side of the coin, we see the need to address biases in university reward structures-for example, tenure and promotion expectations - to increase faculty commitment to community engagement. 
While these areas for further inquiry suggest that this work remains challenging, there are real rewards for both community and academic participants. As one community participant at the roundtable discussion in May 2013 said:

This is a whole lot of fun! For community organizations, the fact is we are not getting anything else out of it - there is no money, no prestige, very little political traction a lot of the time-but we are having fun! (CAFS Roundtable, 2013).

We wish to end on this note, in order to encourage ongoing relationship-building and experimentation.

\section{References}

Andrée, P. (2007). The food bank as classroom: Community-based education for teaching and social change. New Community Quarterly, 4(4), 45-51.

BCFSN/CFICE. (2013). Collaborative Research Guidelines. CFICE CFS hub project 3, 2012: Cross-Cultural Food Networks: Building and Maintaining Inclusive Food Security Networks to Support Indigenous and Non-Indigenous Communities. Application to Carleton Research Ethics Board. January 4. [Approved February 21, 2013] (on file with authors).

Block, P. (2010). Community: The structure of belonging. San Francisco: Berrett-Koehler Publishers.

Born, P. (2012). Community conversations: Mobilizing the ideas, skills and passion of community organizations, governments, businesses and people. ( $2^{\text {nd }}$ ed). Toronto: BPS Books.

Bringle, R.G., \& Hatcher, J.A. (1996). Implementing service-learning in higher education. Journal of Higher Education, 67(2), 221-239.

CACSL. (2013). Canadian Alliance for Community Service-Learning. Retrieved from http://www.communityservicelearning.ca/en/welcome_what_is.htm

CAFS (2013). Canadian Association for Food Studies. About CAFS. Mission. Retrieved from http://cafs.landfood.ubc.ca/en/?page_id=6

CAFS Roundtable. (2013). Reflections from the Community First: Impacts of Community Engagement Project. Meeting of the Canadian Association for Food Studies. Victoria, British Columbia. June 4. (video recording on file with authors) 
Chapman, D., \& Martin, W. (2013). Cross-Cultural Food Networks: Building and Maintaining Inclusive Food Security Networks to Support Indigenous and Non-Indigenous Communities. BC Food Systems Network. (on file with authors)

Chupp, C., \& Joseph, M. (2010). Getting the most out of service learning: Maximizing student, university and community Impact. Journal of Community Practice, 18, 190212.

FSC (2013). Food Secure Canada. About Us. Vision and Mission. Retrieved from http://foodsecurecanada.org/vision-mission

Hamm, M.W., \& Bellows, A. C. (2003). Community food security and nutrition educators. Journal of Nutrition Education and Behavior, 35(1), 37-43.

Harrison, B., Nelson, C.H., \& Stroink, M.L. (2013). Being in community: A food security themed approach to public scholarship. Journal of Public Scholarship and Higher Education, 3, 91-110.

Macaulay, A.C., Commanda, L.E., Freeman, W.L., Gibson, N., McCabe, M.L., Robbins, C.M., \& Towhig, P.L. (1999). Participatory research maximizes community and lay involvement. British Medical Journal, 319, 774-778.

McCarthy, A. \& Tucker, M. (1999). Student Attitudes Towards Service-Learning: Implications for Implementation. Journal of Management Education, 23, 554-573.

Nasr, J., \& Komisar, J. (2012). Integration of food and agriculture into urban planning and design practices. In A. Viljoen \& J. Wiskerke (Eds.), Sustainable Food Planning: Evolving Theory and Practice (pp. 47-58). Wageningen, the Netherlands: Wageningen Academic Publishers.

Nelson, C.H., \& McPherson, D.H. (2004). Contextual fluidity: An emerging practice model for helping. Rural Social Work, 9, 199-209.

Nelson, C.H., Stadey, M., \& Lyons, A. (2005). Community-academic research partnership: A key recipe for food security. In A.M. Kirbyson (Ed.), Recipes for Success: A Celebration of Food Security Work in Canada (pp. 27-31). Winnipeg: Social Planning Council of Winnipeg.

Nelson, C.H., \& Stroink, M.L. (2012, November). Hubs of knowledge creation: Exploring the potential for knowledge co-generation within the post-secondary academy Association of Commonwealth Universities. Interact, 3.

Nelson, C.H., \& Stroink, M.L. (2013). CFICE FSRN Case Study Report. (on file with authors). 
Schnarch, B. (2004). Ownership, control, access, and possession (OCAP) or self-determination applied to research: A critical analysis of contemporary First Nations research and some options for First Nations communities. Journal of Aboriginal Health, 1(1), 80-95.

Smith, L.T. (1999). Decolonizing methodologies: Research and Indigenous Peoples. New York: Zed Books.

Stoecker, R. (2008). Challenging institutional barriers to community-based research. Action Research, 6(1), 49-67.

Stoeker, R., \& Tryon, W., with Hilgendorf, A. (2009). The unheard voices: Community organizations and service-learning. Philadelphia: Temple University Press.

Strand, K., Marullo, S., Cutforth, N., Stoecker, R., \& Donohue, P. (2003). Community-based research and higher education: Principles and practices. San Francisco: John Wiley and Sons.

Stroink, M.L., \& Nelson, C.H. (2013). Complexity and food hubs: Five case studies from Northern Ontario. Local Environment: International Journal of Justice and Sustainability, 18(5), 620-635. Retrieved from http://www.tandfonline.com/eprint/pdPhN2FtTy9KDNiZJu3G/full\#.UkjFGWRAR15

Sullivan, M., Kone, A., Senturia, K., .,Chrisman, N., Criske, S., \& Krieger, J. (2001). Researcher and researched-community perspectives: Toward bridging the gap. Health Education and Behavior, 28(2), 130-149.

Swords, A.C., \& Kiely, R. (2010). Beyond pedagogy: Service learning as movement building in higher education. Journal of Community Practice, 18, 148-170.

van de Sande, A., \& Schwartz, K. (2011). Research for social justice: A community-based approach. Halifax: Fernwood Publishing.

Ward K., \& Wolf-Wendel, L. (2000). Community-centered service learning. The American Behavioral Scientist, 43, 767-780.

Waterloo Region Food System Roundtable. (2013). Retrieved from http://www.wrfoodsystem.ca/aboutus 